\title{
Influencing the Relationship between Job Clarity and Turnover Intention through User Training During Enterprise System Implementation
}

\author{
Rick L. Brattin, Joshua M. Davis, Sheryl Brahnam \\ Department of Management and Information Technology, Missouri State University, Springfield, Missouri \\ RickBrattin@MissouriState.edu, JoshuaDavis@MissouriState.edu, SBrahnam@MissouriState.edu
}

\begin{abstract}
Enterprise system (ES) implementations introduce pervasive and disruptive change to organizations. End-users struggling to cope with such change often develop an internal self-preservation narrative that, if not managed, can lead to employee turnover. Turnover is a visibly-assertive response to ES implementations that has lasting negative effects on organizations. The job role literature suggests that an individual's intention to leave an organization is greater when they lack clarity concerning their own work tasks and their role in achieving broader organizational goals. These clarity perceptions evolve during ES implementations as individuals become aware that their existing job context is no longer relevant to the postimplementation organization. It seems likely that the strength of relationship between job clarity and turnover intention will also evolve during this time. Accordingly, this study uses PLS-SEM multi-group analysis to examine changes in this relationship during an ES implementation at a Fortune 100 manufacturer and finds a significant increase in the influence of job clarity deficiencies on turnover intention following enduser training. These results suggest that ES implementation teams should focus their efforts on building job clarity of the post-implementation work context.
\end{abstract}

Keywords: Enterprise System Implementation, End-User Training, Job Clarity, Turnover Intention, PLS-SEM

\section{Introduction}

In a recent forecast of worldwide IT spending (January 16, 2018), Gartner, Inc., a leading IT research and advisory company, projects 2019 spending on enterprise software at \$421B USD. Enterprise system (ES) implementations allow organizations to institute new business processes, procedures, and practices which might not otherwise be possible without large integrated technology solutions (Ojiako, Chipulu, Maguire, Akinyemi, \& Johnson, 2012; Amani \& Fadlalla, 2016). While such implementations can enhance organizational performance, increase competitive advantages, and position firms for future growth, the toll on organizational members can be quite high. One concern is that individuals often view pervasive disruption to traditional routines and technologies as threats to their own organizational status or to their ability to meet perceived performance expectations (Shang, 2012). Threatened individuals exhibit resistant behaviors meant to push back against the threat source (e.g., the ES), thereby jeopardizing ES implementation success (Kim \& Kankanhalli, 2009; Rivard \& Lapointe, 2012). Voluntary turnover is a visibly-assertive and selfpreserving behavior often employed as a last resort by individuals who feel unable to adapt to a disruptive event such as an ES implementation (Beaudry \& Pinsonneault, 2005; Fadel, 2012). Turnover intentions, which form in the time leading up to voluntary turnover, are shaped by the success or failure of an individual's own coping strategies enacted to neutralize these threats (Mai, Ellis, Christian, \& Porter, 2016).

Organizations must effectively manage this perilous time of turnover intention formation in order to achieve ES implementation success (Kim \& Kankanhalli, 2009). Organizations find user training an effective tool for managing turnover intention formation and a variety of other resistance behaviors that undermine ES implementations (Nah \& Delgado, 2006; Rivard \& Lapointe, 2012; Shang, 2012; Esteves, 2014; Amani \& Fadlalla, 2016). User training provides hands-on experience with the new ES, helping individuals to form accurate mental models concerning new work situations and the technologies that will enable their work (Markus \& Tanis, 2000; Abdinnour \& Saeed, 2015; Sykes, 2015). This, in turn, leads individuals to produce higher quality work, reduce work duration, and limit the variety of errors made within their work tasks (Karuppan \& Karuppan, 2008). User training provides clarity of work expectations, thereby lowering an individual's stress caused from a lack of understanding of future performance expectations. Interestingly however, prior research within the broader job role context finds only mixed support for the influence of job clarity on turnover intention (Fisher \& Gitelson, 1983; Fried, Shirom, Gilboa, \& Cooper, 2008). 
Possible explanations for the discrepancy are that 1) the influence of job clarity on turnover intention dissipates over protracted periods of time as an individual applies coping strategies (Burris, Detert, \& Chiaburu, 2008), and 2) ES user training results in substantial changes to the individual's mental model of their work context, rendering past coping efforts less effective. In other words, it is possible that ES user training effectively alters the strength of the relationship of job clarity on turnover intention. While we understand that turnover intentions form when individuals perceive an ES implementation will lead to untenable work situations (Klaus, 2011), surprisingly little research has explored the effect of ES user training on job clarity's influence in the relationship. Based on this discussion, the current study builds upon recent ES implementation and training research (Maditinos, Chatzoudes, \& Tsairidis, 2012; Sudhakar, 2012; Almajali, Masa'deh, \& Tarhini, 2016) by investigating the influence of job clarity on turnover intention both prior to and following an ES user training intervention. Drawing from the job role literature's rich history concerning job clarity (e.g., Sawyer, 1992; Hu \& Liden, 2011; Chiocchio, Rabbat, \& Lebel, 2015; Caillier, 2016), we develop a research model which positions job clarity as two separate sub-constructs to align with processoriented and goal-oriented aspects of ES knowledge (Coulson, Olfman, Ryan, \& Shayo, 2010; Cronan \& Douglas, 2013).

Within the context of ES implementations, turnover intentions form through a process of threat assessment and adaptation attempts (Beaudry \& Pinsonneault, 2005), and through observation of social cues from others impacted by the ES (Felps et al., 2009). Data was collected via a longitudinal field experiment as part of an ES implementation at a subsidiary of a Fortune 100 manufacturer located in the United States. Pre- and posttraining models are statistically compared to determine if the influence of job clarity on turnover intention is greater after the user training intervention. In the sections that follow, we lay out the conceptual background of this research, develop hypotheses, and present the research model. Results are then discussed along with research and practical implications. Overall, this study is driven by the following research question, RQ1: Does user training affect the influence of job clarity on turnover intention during ES implementations?

\section{Turnover and Turnover Intention}

Voluntary turnover occurs when an employee willingly chooses to sever employment ties with their organization (Hom, Lee, Shaw, \& Hausknecht, 2017). A recent Bureau of Labor Statistics press release (2017) suggests that U.S. employees voluntarily leave their organizations at a rate of 2.2 percent per month. Turnover results in substantial impact to the organization in terms of cost (possibly exceeding $100 \%$ of salary for the position), work disruptions, and loss of organizational memory (Allen, Bryant, \& Vardaman, 2010). Turnover is found to disrupt operational outcomes (Hausknecht, Trevor, \& Howard, 2009), to reduce financial performance (Heavey, Holwerda, \& Hausknecht, 2013), and to undermine competitive advantage by way of knowledge spillover to competitors (Agarwal, Ganco, \& Ziedonis, 2009). The time leading up to a voluntary turnover event involves a cognitive shift for an individual as they detach from the organization (Burris et al., 2008).

Turnover intentions can lead to deviant work place behaviors (Bennett \& Robinson, 2000), thereby explaining the emergence of visibly assertive resistance by those struggling to cope with changes imposed by the ES (Fadel, 2012). While generally considered the most proximate predictor of the turnover event itself, turnover intention is recognized at a malleable construct with its relationship to turnover subject to intervening factors (Hom \& Kinicki, 2001; Hom, Mitchell, Lee, \& Griffeth, 2012). If turnover intentions are not managed then visibly assertive resistance behaviors, including turnover, often spread contagiously to others in the organization who are also impacted by the ES (Felps et al., 2009). Surprisingly however, past metaanalytic studies acknowledge only equivocal support for the relationship between job clarity and turnover intention (e.g., Fisher \& Gitelson, 1983; Fried et al., 2008). Inconsistency is found across multiple disciplines such as marketing, management, and human resources. Even among studies using the same instrument, such as Rizzo, et al. (1970), some find support (Brown \& Peterson, 1993; Low, Cravens, Grant, \& Moncrief, 2001; Jaramillo, Mulki, \& Solomon, 2006; De Clercq \& Belausteguigoitia, 2017), while others do not (Bedeian \& Armenakis, 1981; Kemery, Bedeian, Mossholder, \& Touliatos, 1985; Singh, Goolsby, \& Rhoads, 1994; Netemeyer, Brashear-Alejandro, \& Boles, 2004). This discrepancy is at odds with ES implementation 
research, which provides strong support for the role user training plays managing turnover intentions (Nah \& Delgado, 2006; Rivard \& Lapointe, 2012; Shang, 2012; Esteves, 2014).

Process Clarity and Goal Clarity: The job role literature explores job activities, effort expectancies, and the congruence thereof among individuals and their employers (Parker, Morgeson, \& Johns, 2017). According to role theory, organizations must provide a clear set of responsibilities for each organizational position, thus enabling managers to effectively evaluate the performance of individuals holding those positions (Kahn, Wolfe, Quinn, \& Snoek, 1964; Fields, 2002). Moreover, individuals lacking clarity of job-related expectancies over prolonged periods of time may expend valuable and finite cognitive resources in an effort to cope with and neutralize resulting stress (Fields, 2002). Role ambiguity, an early and well-studied job clarity construct, is defined as a lack of necessary information regarding role expectations for a given organizational position, (Rizzo et al., 1970). When cognitive demand resulting from role ambiguity exceeds an individual's cognitive capacity, work attitudes and performance will likely suffer (Erera-Weatherley, 1996). Role ambiguity is generally found to correlate positively with stress-aligned constructs (e.g., job-induced psychological strain, exhaustion, depersonalization, reduced accomplishment) and to correlate negatively with positive job constructs (e.g., job satisfaction, job performance, employee engagement).

The Rizzo, et al. (1970) role ambiguity scale is arguably the most used within the literature. It has evolved through a substantial amount of work dedicated to addressing shortcomings such as criticisms of content validity (King \& King, 1990; Smith, Tisak, \& Schmieder, 1993), over reliance on measurement items with comfort wording vs. stress wording (House, Schuler, \& Levanoni, 1983), and translational issues of crossnational studies (Peterson et al., 1995). Sawyer (1992), developed and tested a two-subscale version of the role ambiguity construct in response to calls to explain inconsistent and contradictory findings. Building upon components of the Kahn et al. (1964) definition of role ambiguity, Sawyer defined a process-oriented construct representing means-end knowledge, and a goal-oriented construct representing an individual's understanding of their rights, duties, and responsibilities within their organization. Items for both constructs were measured on a response scale ranging from very uncertain to very certain, and thus were termed clarity as opposed to ambiguity. Process clarity and goal clarity have subsequently been shown as important antecedents to many work-related contexts (Hu \& Liden, 2011; Chiocchio et al., 2015; Caillier, 2016).

Hypothesis Development: The research framework is shown in Figure 1. The box labeled "Time-dependent sub-model" depicts constructs and relationships under consideration both prior to and after user training. We define turnover intention as an employee's belief they will voluntarily leave their current employer (Mai et al., 2016). The antecedents of turnover intention in the model reflect an individual's perceived understanding work task enablement via the ES, and the consequences of their work in relation to the broader organization. Within this context, work tasks are particular items of work which, when performed, have a recognizable beginning and end (Byström \& Hansen, 2005). Individuals require knowledge of ES tools and procedures that enable work tasks execution, and of the necessary sequencing among multiple work tasks within a larger work stream (Coulson et al., 2010). We therefore define process clarity as the extent to which an individual is certain about how and when to perform their work tasks. Furthermore, individuals perform work tasks pursuant to organizational goals and objectives (Byström \& Hansen, 2005). Accordingly, individuals require knowledge concerning goal attainment within their own role and with respect to broader organizational processes (Coulson et al., 2010). We define goal clarity as the extent to which an individual is certain about their work tasks with respect to organizational goals and objectives. Goal clarity, as presented here, closely aligns with the Rizzo, et al. (1970) role ambiguity construct used in many prior job clarity studies. Sawyer (1992, p. 130) elaborated this point by suggesting, five of the six items Rizzo, et al. (1970) chose to represent role ambiguity concern rights, duties, and responsibilities". High role ambiguity (i.e., low goal clarity) intensifies one's turnover intention due to stress resulting from low understanding of organizational expectations (Brown \& Peterson, 1993; De Clercq \& Belausteguigoitia, 2017; Jaramillo et al., 2006; Low et al., 2001). We therefore expect goal clarity to negatively influence turnover intention. Process clarity reflects an individual's understanding of how and when to perform their work tasks. This type of clarity is commonly referred as "means-end knowledge" and refers to an individual's tactical understanding of how and when to perform work tasks in order to achieve work-related expectations (Kahn et al., 1964). 
Figure 1: Research Framework

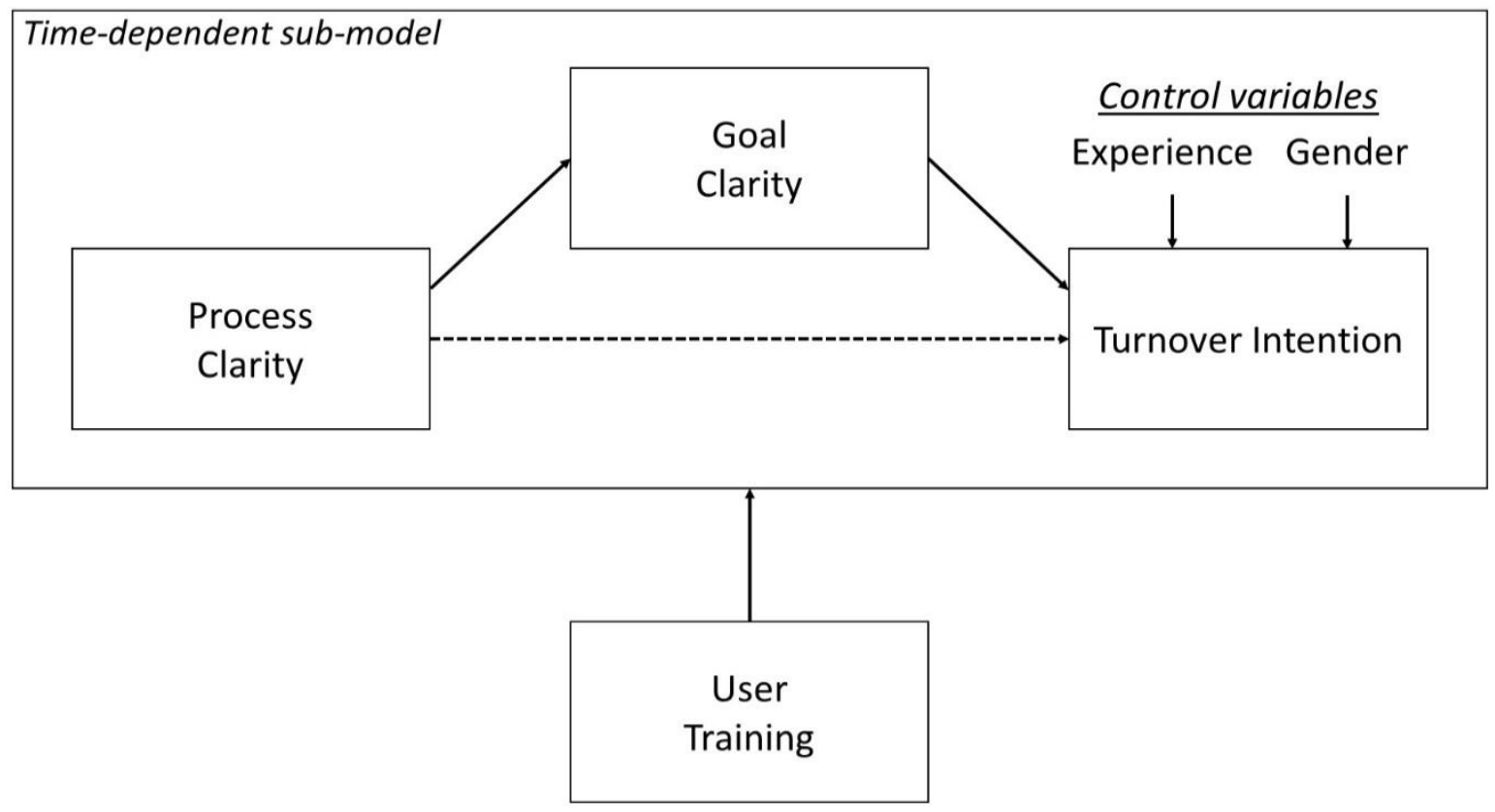

The dashed line represents the direct path necessary to test mediation: PCL $\rightarrow G C L \rightarrow T I N$

Sawyer (1992) argued for (and found support for) a causal path from process clarity to goal clarity on the basis that individuals may infer knowledge of work goals directly from exposure to work tasks. In contrast, simply understanding one's goals may not provide insight to the tasks that allow one to achieve those goals. We therefore expect process clarity to positively influence goal clarity. Finally, it seems likely that an individual will feel more threatened by not understanding their work tasks with respect to organizational goals and objectives than with respect to how and when the work tasks should be performed. Sawyer (1992) found a similar mediated relationship of process clarity to antecedents of goal clarity. Therefore, we expect process clarity to negatively influence turnover intention, but only indirectly through goal clarity. User training is a common support structure offered during ES implementations to help individuals comprehend the new ES and the role it will play in their daily work (Markus \& Tanis, 2000; Sykes, 2015). It provides indepth exposure to new work tasks and goals, accelerating the formation of process clarity and goal clarity of the post-implementation work context (Coulson et al., 2010; Cronan \& Douglas, 2013; Karuppan \& Karuppan, 2008). In this study we consider user training a pivotal, and possibly stress-inducing, event where the postimplementation work context becomes salient and stress-related cognitions and behaviors begin to materialize. It is likely here when the focal concerns of process clarity and goal clarity shift from existing work tasks and goals to post-implementation work tasks and goals. We therefore expect the influence of process clarity and goal clarity on turnover intention to be greater after user training. We offer the following hypotheses:

H1: The negative influence of goal clarity on turnover intention will be stronger after user training than before user training.

H2: The negative influence of process clarity on turnover intention (mediated by goal clarity) will be stronger after user training than before user training.

As already described, we expect process clarity to exert a positive influence on goal clarity prior to user training. This is because knowledge of one's work tasks should to some extent provide insight of how those work tasks impact larger organizational processes (Sawyer, 1992). There is evidence to support that ES user training similarly promotes understanding of higher-level work goals and objectives (Cronan \& Douglas, 
2013). It therefore seems likely that process-clarity positively influences goal clarity regardless of the focal work context. We offer the following hypothesis:

H3: The positive influence of process clarity on goal clarity will be of similar strength before and after user trainings.

\section{Research Method}

Research Site and Participants: A field study was conducted as part of a market-leading ES implementation at a wholly owned subsidiary of a Fortune 100 food manufacturing firm located in the United States. The parent organization has owned the subsidiary for approximately 25 years, though the subsidiary has been in operation for nearly 100 years. A major goal of the ES implementation is to standardize informal and inefficient business processes, particularly those involving the procurement of supplies and materials for both operational and administrative functions. These processes were allowed to evolve over many years according to individual departmental needs, resulting in considerable losses in terms of redundancies, lack of visibility, and inconsistencies. The ES implementation imposed new and integrated procurement processes with the organizational goals of increasing purchasing power, reducing holding costs through inventory optimization, and improving supplier management. A considerable number of work tasks and goals changed as the subsidiary transitioned from a reactionary, needs-based approach to a centrally managed procurement operation focused on managing organizational risks and costs.

In coordination with the new ES rollout, the implementation team conducted a hands-on system training session (duration: 8 hours) for employees whose work tasks and goals fell within the scope of new procurement processes. Approximately four weeks prior to training (T1), each trainee was asked to complete a survey including demographic and construct assessment items. As part of the survey, participants were informed that the study was part of an academic research project and that participation was voluntary and confidential. Immediately following the training session (T2) each trainee was asked to complete a follow-up survey, again voluntary and confidential. The 57 participants (26 males, 31 females) who returned both surveys averaged 11.1 years $(S D=8.1$ ) of experience with the subsidiary. The result is 114 observations available for analysis. This is well within the sample size guidelines of at least ten times the largest number of structural paths directed at a particular construct, and the number needed to achieve a statistical power of $80 \%$ for detecting $\mathrm{R}^{2}$ values of at least 0.25 (Hair, Hult, Ringle, \& Sarstedt, 2017).

Measures: The questionnaire items were adapted from validated instruments from the job role and ES implementation literatures. All items were measured on a seven-point Likert-type scale $(1=$ strongly disagree to 7 = strongly agree). Table A.1 in appendix A provides the constructs, items and sources of the measures used in this study. Turnover intention was measured with the four-item scale used. Goal clarity and process clarity were each measured with the five item scales developed by Sawyer (1992). User training is a dummy variable coded " 0 " for pre-training (T1) and "1" for post-training (T2). The dummy variable allowed us to examine the moderating effect of user training on the relationships between process clarity, goal clarity, and turnover intention. Months of company experience and gender were treated as control variables. Participants were asked to specify their time of service with the company in years and months. The years were then divided by twelve and added to the months to arrive a total company experience measured in months. A single item captured gender ( $0=$ male; $1=$ female $)$.

Research Method: This study explores moderating influence of user training on the relationship between job clarity and turnover intention. Accordingly, we conduct a multi-group analysis (MGA) of time-dependent submodel of Figure 1 using the user training dummy variable as a moderator. MGA is appropriate when path coefficients and other model parameters must be statistically compared between the subsamples formed by a categorical moderator (Hair et al., 2017). Specifically, MGA tests the null hypothesis that path coefficients between two groups (e.g., before training and after training) are not significantly different (Hair, Sarstedt, Ringle, \& Gudergan, 2018). 


\section{Results}

We start by attempting to rule out potential confounding influences on the model results. First, we established that participants perceive a substantial transformation to their post-implementation job context after user training. A low transformation condition will likely result in limited change to the influence of the clarity constructs on turnover intention. As detailed in Appendix B, two manipulation checks indicate that these individuals strongly believe the ES implementation will change their work tasks and goals. Next, we look for differences in each construct values at T1 and T2 as these might introduce additional influence on path coefficients. Descriptive statistics are reported for T1 and T2 in Table 1. Independent samples t-tests of find non-significant differences between constructs at T1 a T2 (goal clarity: $\mathrm{t}(112)=.647$; process clarity: $\mathrm{t}$ $(112)=.688$; turnover intention: $\mathrm{t}(112)=-1.308)$. Finally, we compare correlations among constructs at T1 and T2 using Fisher's Z-tests. As expected, we find the only change to correlational strength from T1 to T2 is between goal clarity and turnover intention.

Table 1: Descriptive Statistics

\begin{tabular}{lccccccc}
\hline \multicolumn{1}{c}{ Construct } & Mean & SD & $\mathbf{1}$ & $\mathbf{2}$ & $\mathbf{3}$ & $\mathbf{4}$ & $\mathbf{5}$ \\
\hline Prior to training (T1) & & & & & & & \\
1. Company experience & 133.49 & 97.22 & $\mathrm{n} / \mathrm{a}$ & & & & \\
2. Gender & $\mathrm{n} / \mathrm{a}$ & $\mathrm{n} / \mathrm{a}$ & .132 & $\mathrm{n} / \mathrm{a}$ & & & \\
3. Goal clarity & 5.75 & 1.02 & -.150 & .072 & .863 & & \\
4. Process clarity & 5.26 & 1.12 & -.259 & .259 & $.652^{* *}$ & .859 & \\
5. Turnover intention & 2.10 & 1.22 & -.173 & -.012 & -.225 & -.129 & .861 \\
& & & & & & & \\
After training (T2) & Mean & SD & $\mathbf{1}$ & $\mathbf{2}$ & $\mathbf{3}$ & $\mathbf{4}$ & $\mathbf{5}$ \\
$\quad$ Construct & 133.49 & 97.22 & $\mathrm{n} / \mathrm{a}$ & & & & \\
1. Company experience & $\mathrm{n} / \mathrm{a}$ & $\mathrm{n} / \mathrm{a}$ & .132 & $\mathrm{n} / \mathrm{a}$ & & & \\
2. Gender & 5.63 & 1.01 & -.120 & .131 & .887 & & \\
3. Goal clarity & 5.12 & 1.17 & -.127 & .016 & $.759^{* *}$ & .870 & \\
4. Process clarity & 2.41 & 1.32 & -.142 & -.059 & $-.565^{* *}$ & $-.386^{* *}$ & .847 \\
5. Turnover intention & & & & & & & \\
& & & & & & & \\
Absolute differences (T2 - T1) & Mean & SD & $\mathbf{1}$ & $\mathbf{2}$ & $\mathbf{3}$ & $\mathbf{4}$ & $\mathbf{5}$ \\
$\quad$ Construct & $\mathrm{n} / \mathrm{a}$ & $\mathrm{n} / \mathrm{a}$ & & & & & \\
1. Company experience & $\mathrm{n} / \mathrm{a}$ & $\mathrm{n} / \mathrm{a}$ & .000 & & & & \\
2. Gender & 0.12 & 0.29 & .030 & .059 & & & \\
3. Goal clarity & 0.14 & 0.20 & .132 & .240 & .107 & & \\
4. Process clarity & 0.31 & 0.24 & .031 & .047 & $.340^{*}$ & .257 &
\end{tabular}

Square root of the average variances extracted (AVE) are found on diagonal of the correlation matrices $* \mathrm{p}<.05 ; * * \mathrm{p}<.01$

We conducted a multi-group analysis (MGA) of the path model depicted in Figure 1 using partial least squares structural equation modeling (PLS-SEM) with Smart PLS 3, a component-based path modeling software (Ringle, Wende, \& Becker, 2015). The PLS approach to SEM has higher statistical power than covariancebased SEM methods (e.g. LISREL) for small sample sizes (Reinartz, Haenlein, \& Henseler, 2009). We compute significance levels within the MGA by bootstrapping to 500 iterations. As detailed in Appendix B, the measurement model was assessed as follows at both T1 and T2. All measurement items loaded at 0.70 or higher on their respective constructs except one (Hulland, 1999). That item was subsequently removed from analysis. All constructs demonstrate high internal consistency well above the recommended threshold of 0.70 (Bagozzi \& Yi, 1988; Hair, Black, Babin, Anderson, \& Tatham, 2006). MGA indicates no difference in internal consistency measured at T1 and T2. The average variance extracted (AVE) of all constructs measured 0.847 or greater, far exceeding the requirement for convergent validity of 0.50 (Bagozzi \& Yi, 1988; Hair et al., 2017). Finally, all constructs satisfy three separate criteria for discriminant validity: A) item loadings for each construct are greater than cross-loadings on other constructs (Chin, 1998); B) the square root of each 
constructs AVE is greater than its correlation with other constructs (Fornell \& Larcker, 1981), and C) The heterotrait-monotrait ratios (HTMT) of the correlations fall well below the threshold of 0.90 (Jörg Henseler, Ringle, \& Sarstedt, 2015).

The structural model is assessed by examining predictive capabilities and the relationships between constructs. All variance inflation factors (VIF) are well below thresholds for multicollinearity concerns (Hair, Ringle, \& Sarstedt, 2011). The single significant influence among the control variables was company experience on turnover intention at T2 $(\beta=-0.217, \mathrm{p}<.05)$. Assessments of predictive accuracy and predictive power fall within desired guidelines (Geisser, 1974; Cohen, 1988; Chin, 1998; Jorg Henseler, Ringle, \& Sinkovics, 2009). The standardized path coefficients appear in Table 2 and Figure 2 presents the full path model results. At T1 the effect of goal clarity on turnover intention was non-significant. At T2 goal clarity exhibits a strong negative influence on turnover intention $(\beta=-0.671, p<.001)$. MGA indicates that the relationship is much stronger at T2 (difference $=0.441, \mathrm{p}<.05$ ), thus supporting H1. Next, we test the relationship of process clarity to turnover intention mediated by goal clarity according to guidelines offered. At T1 both the indirect and direct effects of process clarity on turnover intention are non-significant, indicating no influence. At T2 however, the indirect effect of process clarity on turnover intention is significant $(\beta=-0.509, \mathrm{p}<.001)$ and the direct effect is non-significant. This indicates the relationship is fully mediated by goal clarity at T2. MGA finds the indirect effect much stronger at T2 (difference $=0.359, \mathrm{p}<.05$ ) and the difference in direct effects non-significant, thus supporting H2. Finally, we test the direct influence of process clarity on goal clarity. The relationship is strong and significant at both $\mathrm{T} 1(\beta=0.652, \mathrm{p}<.001)$ and T2 $(\beta=0.759, p<.001)$. MGA finds the difference in strength between T1 and T2 to be non-significant, thus supporting $\mathrm{H} 3$.

Table 2: Standardized Path Coefficients

\begin{tabular}{lccc}
\hline $\begin{array}{l}\text { Prior to training (T1) } \\
\text { Path }\end{array}$ & Direct Effect & Indirect Effect & Total Effect \\
Co. experience -> Turnover intention & -0.226 & -0.226 \\
Gender -> Turnover intention & 0.048 & & 0.048 \\
Goal clarity -> Turnover intention & -0.230 & -0.230 \\
Process clarity -> Turnover intention & -0.050 & -0.150 & -0.200 \\
Process clarity -> Goal clarity & $0.652^{* * *}$ & & $0.652^{* * *}$ \\
After training (T2) & & \\
Path & Direct Effect & Indirect Effect & Total Effect \\
Co. experience -> Turnover intention & $-0.217^{*}$ & & $-0.217^{*}$ \\
Gender -> Turnover intention & 0.056 & & 0.056 \\
Goal clarity -> Turnover intention & $-0.671^{* * *}$ & & $-0.671^{* * *}$ \\
Process clarity -> Turnover intention & -0.095 & $-0.509^{* * *}$ & $-0.414^{* * *}$ \\
Process clarity -> Goal clarity & $0.759^{* * *}$ & & $0.759^{* * *}$ \\
& & \\
Absolute difference (T2 - T1) & & & \\
Path & Direct Effect & Indirect Effect & Total Effect \\
Co. experience -> Turnover intention & 0.009 & & 0.009 \\
Gender -> Turnover intention & 0.009 & & 0.009 \\
Goal clarity $\rightarrow>$ Turnover intention & $0.441^{*}$ & & $0.441^{*}$ \\
Process clarity -> Turnover intention & 0.145 & $0.359^{*}$ & 0.145 \\
Process clarity -> Goal clarity & 0.108 & & 0.108 \\
\hline p $<.05 ; * * \mathrm{p}<.01 ; * * * \mathrm{p}<.001$ & &
\end{tabular}

Overall, the results confirm the hypotheses and shed important light on the interplay among elements of job clarity, training, and turnover intention. Difference testing between pre-training and post-training datasets provides strong support for the moderating influence of ES training on the relationship between goal clarity 
and turnover intention, supporting H1. Importantly, no significant relationship between goal clarity and turnover intention could be found prior to training, with a strong negative relationship emerging after training. In addition to finding support for $\mathrm{H} 1$, the emergence of an enhanced indirect relationship between process clarity and turnover intention in the post-training results support $\mathrm{H} 2$. Finally, as predicted in $\mathrm{H} 3$, the results show a consistently strong relationship between process clarity and goal clarity. While training marginally enhanced this relationship, the results generally point to a stable and strong relationship between process clarity and goal clarity that is not significantly altered by training efforts.

\section{Figure 2: Path Model Results}
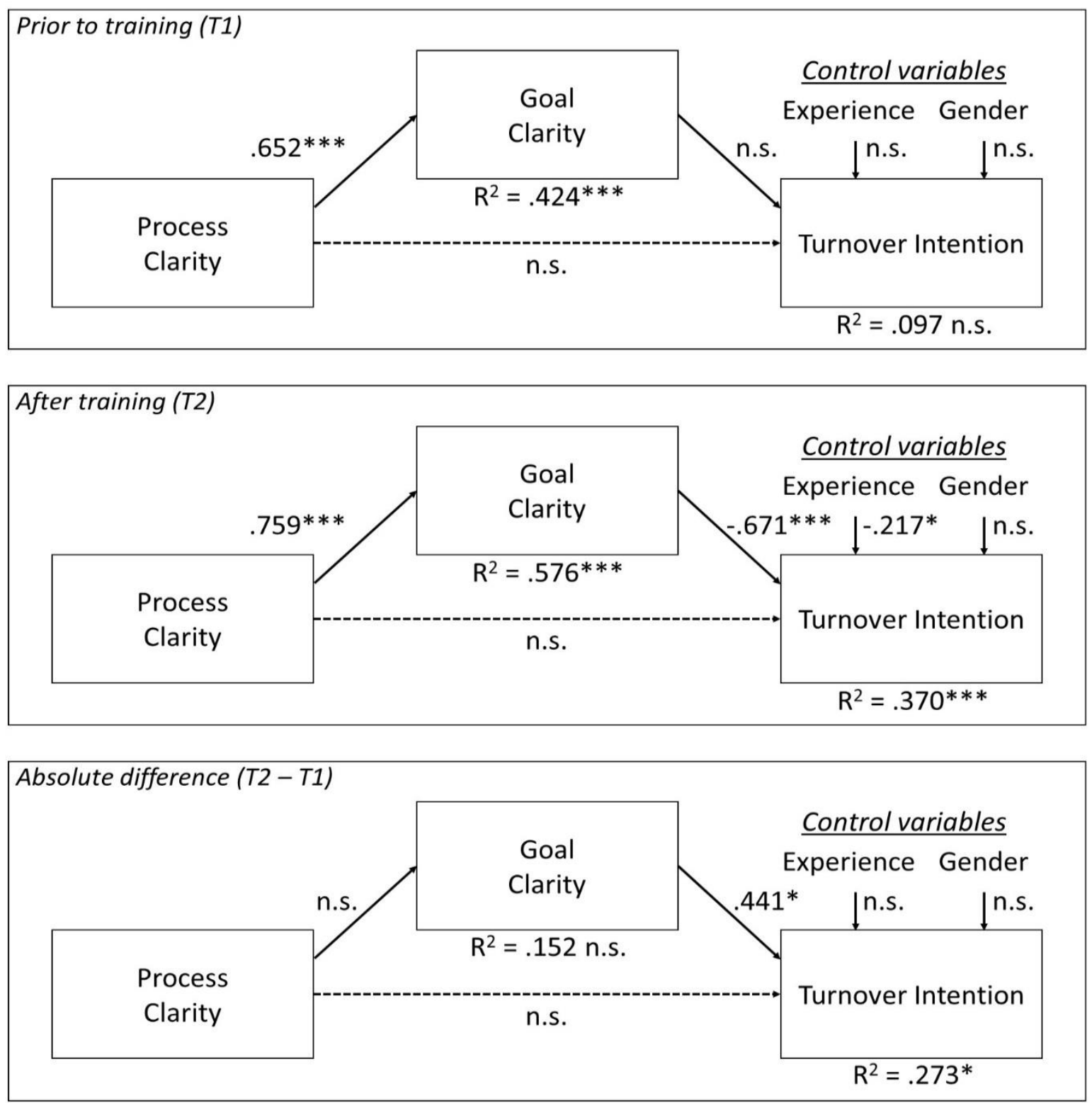

The dashed line represents the direct path necessary to test full mediation: PCL $\rightarrow G C L \rightarrow T I N$

${ }^{*} p<.05 ;{ }^{* *} p<.01 ;{ }^{* * *} p<.001$ 


\section{Discussion and Conclusion}

To date, the job role literature has found only equivocal support for the relationship between job clarity and turnover intention (Fisher \& Gitelson, 1983; Fried et al., 2008). Our deconstructed approach to evaluating this relationship contributes new understanding about why. Specifically, we show that the influence on turnover intention is not uniform across both aspects of job clarity-process clarity and goal clarity. Rather, goal clarity mediates the influence of process clarity on turnover intention; a relationship which is moderated by the provision of end-user training. Taken further, this study shows that provision of end-user training plays an important moderating role in the relationship between process clarity, goal clarity, and turnover intention; providing addition explanation regarding inconsistency in past findings. Two important research implications emerge from these findings. For one, the relationship between job clarity and turnover intention is more complex than an aggregate construct like job clarity can capture.

As such, future research on the relationship between job clarity and coping factors like turnover intention should take a deconstructed view of job clarity that separately considers process clarity and job clarity. Second, this relationship needs to be considered in light of relevant contingent variables that are contextualized to the research setting and my moderate the relationship between goal clarity and turnover intention. For managers, the results tell a very compelling story about the relationships among job clarity, turnover intention, and the role of ES training in the implementation context. Specifically, this study shows that the relationship between knowing what tasks to perform (process clarity) and why the tasks matter (goal clarity) is a stable one that is relatively unaffected by training interventions. However, the influence of these two factors on mitigating turnover is nonexistent-until the organization invests in the success of the individual employee. This phenomenon can be understood through the lens of Social Exchange Theory (Cropanzano \& Mitchell, 2005), which posits that employees hold long-term views the workplace in terms of the perceived quality of exchange relationships with different organizational foci (e.g., the organization as a whole, the IS department, a direct supervisor, etc.) (Davis, 2013), Guided by the norm of reciprocity, these relationships evolve over time into trusting, loyal commitments guided by reciprocation of beneficial acts (Cropanzano \& Mitchell, 2005). The quality of exchange between an individual and the organization plays an important role in turnover intention and is assessed based on the organization's readiness to provide the necessary aid to perform effectively and recognize work effort (Davis, 2013).

In the context of the current study, these theoretical tenets suggest that the value of training as an intervention for mitigating turnover during disruptive change like ES implementation is primarily symbolic and relational in nature. Two important practical implications emerge from this perspective. First, end user training is essential to mitigating turnover during disruptive change involving IT. Beyond any utilitarian value of training (e.g., competence building, self-efficacy development, etc.), the symbolic value of training can help address turnover by actively demonstrating value of the job role and the employee. Building on the first, the second important implication of this perspective relates to what is covered in training. The findings from this study indicate that training programs solely focused on clarifying one's job in terms of the new system may carry important opportunity costs. Training in this context should be views as an opportunity to impart knowledge and clarity of a role and an opportunity to build/reinforce notions of organizational support for employee's whose routines are disrupted by the newly implemented ES. According to theory and the results of this study, those efforts can influence employees' willingness to persevere through the disruption. This work has a few limitations that should be acknowledged, and results interpreted with necessary caution. The study was carried out at a single organization during a single ES project at a certain level of business process change. Future studies should extend this work through investigation across a variety of industries settings. Further, ES projects are often complex undertakings with varying extents of business process change. No attempt was made to assess the influence of project or environmental characteristics on study outcomes.

Conclusion: This study sought to shed new light on the interplay between job clarity, training, and turnover intention in the ES implementation context. Using a deconstructed view of job clarity, we theorized and tested a model that positions goal clarity as a mediating factor between process clarity and turnover intention. Result of model testing before and after end user training provided strong evidence supports user training as an essential intervention during ES implementations, for mitigating turnover intention in the user base. 
Overall, given the new insights in this study, the doors are open for a fruitful stream of research that builds on this study and further untangles the complex relationships between job clarity, training, and turnover intention in the ES implementation context.

\section{Appendix A - Constructs and Response Scales}

\section{Table A.1. Research Model Constructs and Response Scales}

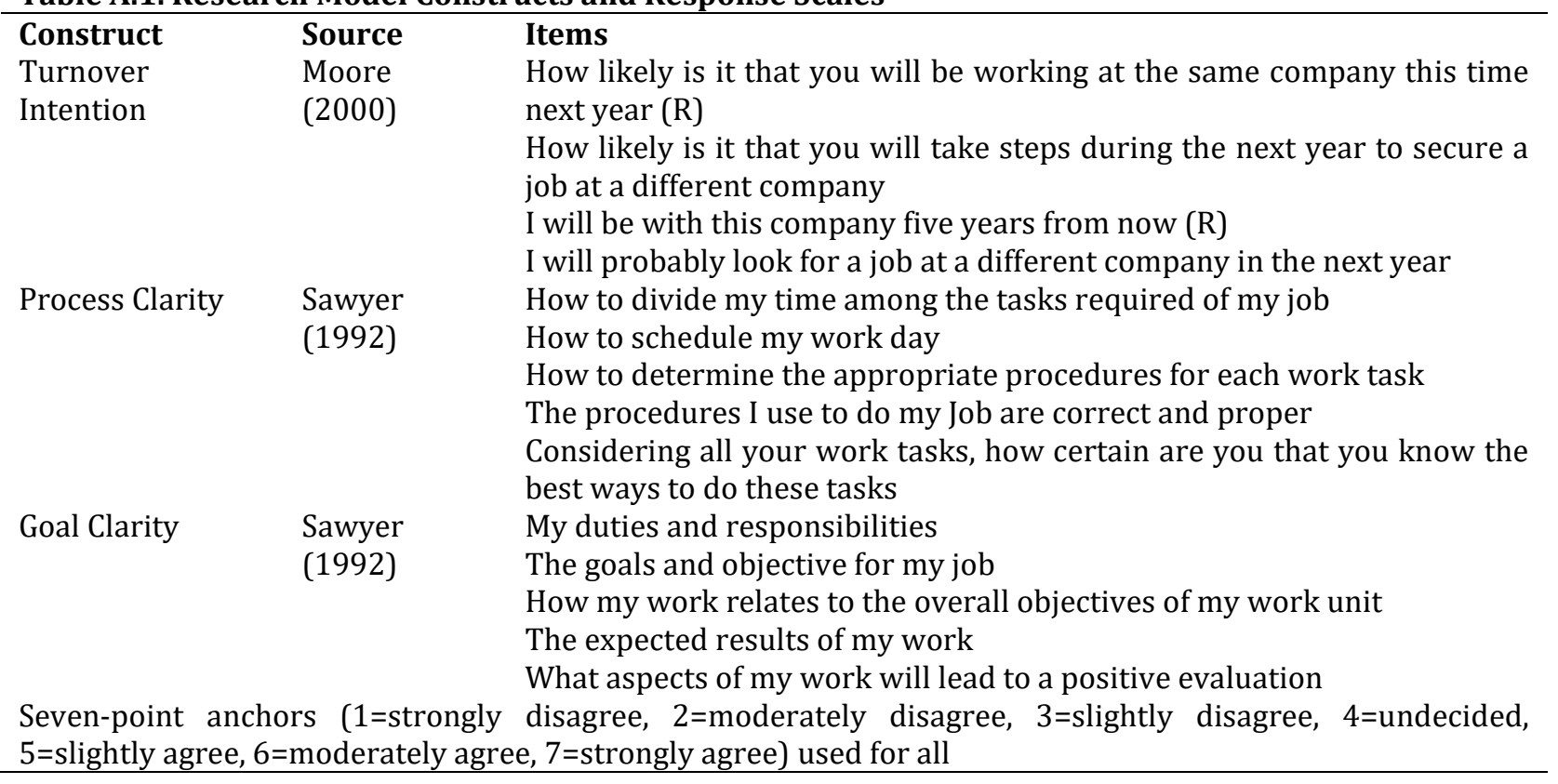

Table A.2. Manipulation Check Construct and Response Scales (not included in research model)

\begin{tabular}{|c|c|c|}
\hline Construct & Source & Items \\
\hline Perceived Job & Morris and & The new process will change my job significantly \\
\hline \multirow[t]{3}{*}{ Transformation } & Venkatesh & The new process will alter my job substantially \\
\hline & $(2010)$ & The new process will make my job very different \\
\hline & & The new process will transform my job greatly \\
\hline Work & Jackson, & Will you decide on the order in which you will do things \\
\hline \multirow{8}{*}{ Control } & Wall, Martin, & Will you decide when to start a piece of work \\
\hline & \& David & Will you decide when to finish a piece of work \\
\hline & (1993) & Will you set your own pace of work \\
\hline & & Will you be able to control how much you produce \\
\hline & & Will you be able to vary how you do your work \\
\hline & & Will you plan your own work \\
\hline & & Will you be able to control the quality of what you produce \\
\hline & & $\begin{array}{l}\text { Will you be able to decide how to go about getting your work in the new } \\
\text { process done }\end{array}$ \\
\hline Seven-point anc & igly & $\begin{array}{l}\text { Will you be able to choose the methods to use in carrying out your work } \\
\text { disagree, } 2=\text { =moderately disagree, } 3=\text { =slightly disagree, } 4=\text { =undecided, } \\
\text { e, } 7 \text { =strongly agree) used for all }\end{array}$ \\
\hline
\end{tabular}

\section{Appendix B - Model Assessment Details}

B.1. Manipulation Check: We include two manipulation checks variables to establish that participants perceived a substantial transformation to their job due to the ES implementation. The response scales are provided in Appendix A, Table A.2. A four-item measure of perceived job transformation (Morris \& Venkatesh, 2010) measured at T2 captured the degree to which the individual believes the new ES will alter 
their job role and expectations. The average perceived job transformation was $5.26(\mathrm{SD}=1.23)$ on a 7 point scale, indicating that participants perceive their new job to be substantially different than under the legacy process. A ten-item measure of work task control (Jackson, Wall, Martin, \& Davids, 1993) was measured at both T1 and T2, reflecting degree to which individuals believe they are free to determine how and when to perform their work tasks. Comparing T1 vs. T2 work task control indicates that individuals perceived lower control at $\mathrm{T} 2(\mathrm{t}=2.44 ; \mathrm{DF}=112 ; \mathrm{p}=0.016)$. Together these two manipulation checks suggest that these participants believe the ES implementation substantially changed their work tasks and goals.

B.2. Measurement Model Estimation: The loadings and cross-loading are shown in Table B.1. Item PCL5 cross-loaded highly both clarity constructs at T2 and was therefore dropped from analysis in both group models. All remaining items loaded at 0.70 or higher on their respective constructs (Hulland, 1999). MGA indicates no difference in item loadings at T1 and T2, except for GCL5 loading significantly higher at T2. As shown in Table B.2, the three multi-item constructs demonstrate high internal consistency with both Cronbach's alpha and composite reliability measuring well above the recommended threshold of 0.70 (Bagozzi \& Yi, 1988; Hair, Black, Babin, Anderson, \& Tatham, 2006). MGA indicates no difference in internal consistency measured at T1 and T2. The average variance extracted (AVE) of the constructs, which range from 0.847 to 0.887 , exceed the threshold of 0.50 required to establish convergent validity at both T1 and T2 (Bagozzi \& Yi, 1988; Hair et al., 2017). Finally, discriminant validity is assessed using the following criteria. Item loadings for each construct are greater than cross-loadings on other constructs (Chin, 1998). Per the Fornell-Larker criterion (Fornell \& Larcker, 1981), the square root of each construct's AVE is greater than its correlation with other constructs. The heterotrait-monotrait ratios (HTMT) of the correlations fall well below the threshold of 0.90 (see Table B.3) (Jörg Henseler, Ringle, \& Sarstedt, 2015), Thus, we find support that all constructs satisfy discriminant validity criteria at both $\mathrm{T} 1$ and $\mathrm{T} 2$.

Table B.1. Loadings and Cross-Loadings

\begin{tabular}{lllllllcccc}
\hline & \multicolumn{4}{c}{ Prior to training (T1) } & \multicolumn{4}{c}{ After Training (T2) } & Abs \\
& Item & GCL & PCL & TIN & t-value & GCL & PCL & TIN & t-value & Diff \\
\hline & GCL1 & 0.874 & 0.663 & -0.151 & $17.628^{* * *}$ & 0.883 & 0.682 & -0.408 & $25.914^{* * *}$ & 0.008 \\
Goal & GCL2 & 0.917 & 0.589 & -0.198 & $25.407^{* * *}$ & 0.874 & 0.689 & -0.367 & $19.464^{* * *}$ & 0.043 \\
Clarity & GCL3 & 0.883 & 0.475 & -0.267 & $21.785^{* * *}$ & 0.895 & 0.642 & -0.651 & $21.046^{* * *}$ & 0.013 \\
(GCL) & GCL4 & 0.925 & 0.663 & -0.163 & $43.198^{* * *}$ & 0.914 & 0.694 & -0.634 & $28.664^{* * *}$ & 0.011 \\
& GCL5 & 0.699 & 0.342 & -0.234 & $9.134^{* * *}$ & 0.869 & 0.666 & -0.402 & $15.053^{* * *}$ & $0.170^{*}$ \\
& PCL1 & 0.461 & 0.843 & -0.097 & $9.459^{* * *}$ & 0.543 & 0.848 & -0.113 & $13.291^{* * *}$ & 0.005 \\
Process & PCL2 & 0.542 & 0.867 & -0.080 & $12.635^{* * *}$ & 0.595 & 0.907 & -0.241 & $20.163^{* * *}$ & 0.040 \\
(PCL) & PCL3 & 0.532 & 0.900 & -0.197 & $31.769^{* * *}$ & 0.751 & 0.880 & -0.515 & $29.769^{* * *}$ & 0.019 \\
& PCL4 & 0.662 & 0.822 & -0.074 & $13.289^{* * *}$ & 0.692 & 0.845 & -0.360 & $20.564^{* * *}$ & 0.022 \\
Turnover & TIN1R & -0.234 & -0.218 & 0.851 & $7.094^{* * *}$ & -0.603 & -0.377 & 0.911 & $41.601^{* * *}$ & 0.060 \\
Intention & TIN2 & -0.154 & -0.042 & 0.832 & $8.486^{* * *}$ & -0.384 & -0.272 & 0.826 & $14.948^{* * *}$ & 0.006 \\
(TIN) & TIN3R & -0.204 & -0.078 & 0.908 & $8.902^{* * *}$ & -0.457 & -0.357 & 0.828 & $8.014^{* * *}$ & 0.080 \\
$* \mathrm{p}<.05 ;$ & TIN4 & -0.177 & -0.113 & 0.850 & $8.280^{* * *}$ & -0.428 & -0.285 & 0.821 & $9.807^{* * *}$ & 0.030 \\
\hline
\end{tabular}

Table B.2. Internal Consistency Reliability

\begin{tabular}{lcccccc}
\hline & \multicolumn{2}{c}{ Prior to training (T1) } & \multicolumn{2}{c}{ After training (T1) } & \multicolumn{2}{c}{ Abs. Diff. (T2 - T1) } \\
Construct & $\boldsymbol{\alpha}$ & CR & A & CR & A & CR \\
\hline Goal clarity & .913 & .936 & .932 & .949 & .019 & .013 \\
Process clarity & .882 & .918 & .896 & .926 & .014 & .008 \\
Turnover intention & .886 & .920 & .870 & .911 & .017 & .009 \\
$\alpha=$ Cronbach's alpha; CR & $=$ composite reliability; All differences non-significant & & \\
\hline
\end{tabular}


Table B.3. Heterotrait-Monotrait Ratios (HTMT)

\begin{tabular}{lcccccccc}
\hline & \multicolumn{3}{c}{ Prior to training (T1) } & \multicolumn{4}{c}{ After training (T2) } \\
Construct & $\mathbf{1}$ & $\mathbf{2}$ & $\mathbf{3}$ & $\mathbf{4}$ & $\mathbf{1}$ & $\mathbf{2}$ & $\mathbf{3}$ & $\mathbf{4}$ \\
\hline 1. Company experience & & & & & & & & \\
2. Gender & .132 & & & & .132 & & & \\
3. Goal clarity & .152 & .115 & & & .127 & .133 & & \\
4. Process clarity & .279 & .267 & .693 & & .143 & .115 & .811 & \\
5. Turnover intention & .163 & .057 & .256 & .159 & .151 & .095 & .601 & .394 \\
\hline
\end{tabular}

B.3. Structural Model: We assess the structural model by examining predictive capabilities and the relationships between the constructs. All variance inflation factors (VIFs) are less than 2.5 and well below the acceptable threshold of 5.0, suggesting the multicollinearity is not an issue (Hair, Ringle, \& Sarstedt, 2011). The single significant influence among the control variables was company experience on turnover intention at T2 $(\beta=-0.217, p<.05)$. This is consistent with prior studies that find tenured individuals exhibit lower propensity to leave an organization (Fleps, 2009). MGA finds a non-significant difference in beta coefficients for company experience between $\mathrm{T} 1$ and $\mathrm{T} 2$, suggesting that the change in the relationship strength due to user training is inconsequential.

B.3.1. Predictive Accuracy: Regarding goal clarity, the model explained $42.4 \%$ of variance at T1 and $57.6 \%$ at T2. The difference of $15.2 \%$ is non-significant (see Table B.4). The variance explained in turnover intention was non-significant at T1. At T2 however, the model explained $37.0 \%$ of the variance and the difference between T1 and T2 of $27.3 \%$ was significant $(\mathrm{p}<.05)$. Following guidance of Cohen (1988) we assess each exogenous construct's contribution to respective endogenous constructs using the following scale of effect sizes ( $\mathrm{f}^{2}$ ): $.02=$ small; $.15=$ medium; .35 = large. As Table B.4 indicates, process clarity exhibits a large effect on goal clarity at both $\mathrm{T} 1$ and $\mathrm{T} 2$, and a large increase from $\mathrm{T} 1$ to $\mathrm{T} 2$. The effect of the company experience control variable on turnover intention was small at both T1 and T2. The difference between T1 and T2 registers as a small increase, but at the lowest end of the scale. The effect of goal clarity on turnover intention was small at T1. At T2 however, the effect grew to medium strength. Neither gender nor process clarity exhibited an effect on turnover intention at T1 or T2. Next we assess the predictive relevance $\left(\mathrm{Q}^{2}\right)$ through blindfolding with an omission distance $=7$ and reviewing the construct cross-validated redundancies (Chin, 1998; Jorg Henseler et al., 2009). Values larger than zero indicate the path model has predictive relevance for a given endogenous construct (Geisser, 1974).

Table B.4. Predictive Accuracy

\begin{tabular}{|c|c|c|c|c|c|c|}
\hline \multicolumn{3}{|l|}{ Prior to training (T1) } & \multicolumn{4}{|c|}{ Effect size of exogenous variables $\mathrm{f}^{2}$} \\
\hline Endogenous variable & $\mathbf{R}^{2}$ & $\mathbf{R}_{\mathrm{adj}}^{2}$ & Co Exp & Gender & GCL & PCL \\
\hline Goal clarity & $.424^{* * *}$ & $.414^{* * *}$ & $\mathrm{n} / \mathrm{a}$ & $\mathrm{n} / \mathrm{a}$ & $\mathrm{n} / \mathrm{a}$ & $.738^{\mathrm{L}}$ \\
\hline Turnover intention & .097 & .027 & .050 & no effect & $.033^{\mathrm{S}}$ & no effect \\
\hline \multicolumn{3}{|l|}{ After training (T2) } & \multicolumn{4}{|c|}{ Effect size of exogenous variables $\mathrm{f}^{2}$} \\
\hline Endogenous variable & $\mathbf{R}^{2}$ & $\mathbf{R}_{\text {adj }}^{2}$ & Co Exp & Gender & GCL & PCL \\
\hline Goal clarity & $.576^{* * *}$ & $.568^{* * *}$ & $\mathrm{n} / \mathrm{a}$ & $\mathrm{n} / \mathrm{a}$ & $\mathrm{n} / \mathrm{a}$ & $1.359^{\mathrm{L}}$ \\
\hline Turnover intention & $.370^{* * *}$ & $.322^{* *}$ & $.072^{\mathrm{s}}$ & no effect & $.291^{\mathrm{M}}$ & no effect \\
\hline \multicolumn{3}{|l|}{ Absolute difference (T2 - T1) } & \multicolumn{4}{|c|}{ Effect size of exogenous variables $\mathrm{f}^{2}$} \\
\hline Endogenous variable & $\mathbf{R}^{2}$ & $\mathbf{R}_{\mathbf{a d j}}^{2}$ & Co Exp & Gender & GCL & PCL \\
\hline Goal clarity & .152 & .154 & $\mathrm{n} / \mathrm{a}$ & $\mathrm{n} / \mathrm{a}$ & $\mathrm{n} / \mathrm{a}$ & $.622^{\mathrm{L}}$ \\
\hline Turnover Intention & $.273^{*}$ & $.294^{*}$ & $.022^{\mathrm{s}}$ & no diff. & $.258^{\mathrm{M}}$ & no diff. \\
\hline \multicolumn{7}{|c|}{$\begin{array}{l}\text { Co Exp = company experience; } \mathrm{GCL}=\text { goal clarity; } \mathrm{PCL}=\text { process clarity } \\
* \mathrm{p}<.05 ; * * \mathrm{p}<.01 ; * * * \mathrm{p}<.001 \\
\text { Effect size } \mathrm{S}=\text { small } \mathrm{M}=\text { medium } \cdot \mathrm{L}=\text { large }\end{array}$} \\
\hline
\end{tabular}


B.3.2. Predictive Power: As shown in Table B.5, the model provides predictive relevance for goal clarity at $\mathrm{T} 1\left(\mathrm{Q}^{2}=.276\right)$ and $\mathrm{T} 2\left(\mathrm{Q}^{2}=.419\right)$, and for turnover intention at $\mathrm{T} 1\left(\mathrm{Q}^{2}=.044\right)$ and $\mathrm{T} 2\left(\mathrm{Q}^{2}=.198\right)$. The effect size $\left(\mathrm{q}^{2}\right)$ of each exogenous construct on the predictive relevance for each respective endogenous construct was calculated as $\left(Q_{\text {included }}^{2}-Q_{\text {excluded }}^{2}\right) /\left(1-Q_{\text {included }}^{2}\right)$, where $Q_{\text {included }}^{2}$ equals the predictive relevance of the entire model and $Q_{\text {excluded }}^{2}$ equals the predictive relevance with the exogenous construct removed from the model (Chin, 1998; Jorg Henseler et al., 2009). The Cohen (1988) effect sizes are appropriate for evaluating $\mathrm{q}^{2}$ (Hair et al., 2017). The $\mathrm{q}^{2}$ calculation is not applicable to process clarity since it is the only predictor of goal clarity. Both company experience and goal clarity exhibit a medium effect size on the predictive relevance of turnover intention at $\mathrm{T} 1$ and $\mathrm{T} 2$.

Table B.5. Predictive Power

\begin{tabular}{|c|c|c|c|c|c|}
\hline \multirow{2}{*}{$\begin{array}{l}\text { Prior to training (T1) } \\
\text { Endogenous variable }\end{array}$} & \multirow[b]{2}{*}{$\mathbf{Q}^{2}$} & \multicolumn{4}{|c|}{ Effect size of exogenous variables $q^{2}$} \\
\hline & & Co Exp & Gender & GCL & PCL \\
\hline Goal clarity & $.276^{*}$ & $\mathrm{n} / \mathrm{a}$ & $\mathrm{n} / \mathrm{a}$ & $\mathrm{n} / \mathrm{a}$ & $\mathrm{n} / \mathrm{a}$ \\
\hline Turnover intention & $.044^{*}$ & $.025^{\mathrm{M}}$ & no effect & $.022^{\mathrm{M}}$ & no effect \\
\hline \multicolumn{2}{|l|}{ After training (T2) } & \multicolumn{4}{|c|}{ Effect size of exogenous variables $q^{2}$} \\
\hline Endogenous variable & $\mathbf{Q}^{2}$ & Co Exp & Gender & GCL & PCL \\
\hline Goal clarity & $.419 *$ & $\mathrm{n} / \mathrm{a}$ & $\mathrm{n} / \mathrm{a}$ & $\mathrm{n} / \mathrm{a}$ & $\mathrm{n} / \mathrm{a}$ \\
\hline Turnover intention & $.198^{*}$ & $.031^{\mathrm{M}}$ & no effect & $.103^{\mathrm{s}}$ & no effect \\
\hline \multicolumn{6}{|c|}{$\begin{array}{l}\text { Co Exp = company experience; GCL = goal clarity; } \mathrm{PCL}=\text { process clarity } \\
\text { * indicates predictive relevance }\end{array}$} \\
\hline
\end{tabular}

\section{References}

Abdinnour, S. \& Saeed, K. (2015). User Perceptions Towards an ERP System. Journal of Enterprise Information Management, 28(2), 243-259.

Agarwal, R., Ganco, M. \& Ziedonis, R. H. (2009). Reputations for Toughness in Patent Enforcement: Implications for Knowledge Spillovers via Inventor Mobility. Strategic Management Journal, 30(13), 1349-1374.

Allen, D. G., Bryant, P. C. \& Vardaman, J. M. (2010). Retaining Talent: Replacing Misconceptions With Evidence-Based Strategies. Academy of Management Perspectives, 24(2), 48-64.

Almajali, D. A., Masa'deh, R. E. \& Tarhini, A. (2016). Antecedents of ERP Systems Implementation Success: a Study on Jordanian Healthcare Sector. Journal of Enterprise Information Management, 29(4), 549-565.

Amani, F. \& Fadlalla, A. (2016). Organizing ERP Research: a Knowledge-Centric Approach. Journal of Enterprise Information Management, 29(6), 919-940.

Bagozzi, R. P. \& Yi, Y. (1988). On the Evaluation of Structural Equation Models. Journal of the Academy of Marketing Science, 16(1), 74.

Beaudry, A. \& Pinsonneault, A. (2005). Understanding User Responses to Information Technology: A Coping Model of User Adaptation. MIS Quarterly, 29(3), 493-524.

Bedeian, A. G. \& Armenakis, A. A. (1981). A Path-Analytic Study of The Consequences of Role Conflict and Ambiguity. Academy Of Management Journal. Academy Of Management, 24(2), 417-424.

Bennett, R. J. \& Robinson, S. L. (2000). Development of a Measure of Workplace Deviance. The Journal of Applied Psychology, 85(3), 349-360.

Brown, S. P. \& Peterson, R. A. (1993). Antecedents and Consequences of Salesperson Job Satisfaction: MetaAnalysis and Assessment of Causal Effects. Journal of Marketing Research (JMR), 30(1), 63-77.

Bureau of Labor Statistics. (2017). Job Openings and Labor Turnover - July 2017 [Press release]

Burris, E. R., Detert, J. R. \& Chiaburu, D. S. (2008). Quitting Before Leaving: The Mediating Effects of Psychological Attachment and Detachment on Voice. Journal of Applied Psychology, 93(4), 912-922.

Byström, K. \& Hansen, P. (2005). Conceptual Framework for Tasks in Information Studies. Journal of the American Society for Information Science \& Technology, 56(10), 1050-1061.

Caillier, J. G. (2016). Does Public Service Motivation Mediate the Relationship between Goal Clarity and both Organizational Commitment and Extra-Role Behaviours? Public Management Review, 18(2), 300-318. 
Chin, W. W. (1998). The Partial Least Squares Approach for Structural Equation Modeling. In G. A. Marcoulides (Ed.), Modern Methods for Business Research. (pp. 295-336). Mahwah, NJ, US: Lawrence Erlbaum Associates Publishers.

Chiocchio, F., Rabbat, F. \& Lebel, P. (2015). Multi-Level Efficacy Evidence of a Combined Interprofessional Collaboration and Project Management Training Program for Healthcare Project Teams. Project Management Journal, 46(4), 20-34.

Cohen, J. (1988). Statistical Power Analysis for the Behavioral Sciences.

Coulson, T., Olfman, L., Ryan, T. \& Shayo, C. (2010). Enterprise Systems Training Strategies: Knowledge Levels and User Understanding. Journal of Organizational \& End User Computing, 22(3), 22-39.

Cronan, T. P. \& Douglas, D. E. (2013). Assessing ERP Learning (Management, Business Process, and Skills) and Attitudes. Journal of Organizational \& End User Computing, 25(2), 59-74.

Cropanzano, R. \& Mitchell, M. S. (2005). Social Exchange Theory: An Interdisciplinary Review. Journal of Management, 31(6), 874-900.

Davis, J. M. (2013). Leveraging the IT Competence of Non-IS Workers: Social Exchange and the Good Corporate Citizen. European Journal of Information Systems, 22(4), 403-415.

De Clercq, D. \& Belausteguigoitia, I. (2017). Reducing the Harmful Effect of Role Ambiguity on Turnover Intentions. Personnel Review, 46(6), 1046-1069.

Erera-Weatherley, P. I. (1996). Coping with Stress: Public Welfare Supervisors Doing Their Best. Human Relations, 49(2), 157-170.

Esteves, J. M. (2014). An Empirical Identification and Categorisation of Training Best Practices for ERP Implementation Projects. Enterprise Information Systems, 8(6), 665-683.

Fadel, K. J. (2012). The Role of Appraisal in Adapting to Information Systems. Journal of Organizational \& End User Computing, 24(4), 18-40.

Felps, W., Mitchell, T. R., Hekman, D. R., Lee, T. W., Holtom, B. C. \& Harman, W. S. (2009). Turnover Contagion: How Coworkers' Job Embeddedness and Job Search Behaviors Influence Quitting. Academy of Management Journal, 52(3), 545-561.

Fields, D. L. (2002). Taking the Measure of Work. Thousand Oaks, CA: Sage Publications, Inc.

Fisher, C. D. \& Gitelson, R. (1983). A Meta-Analysis of the Correlates of Role Conflict and Ambiguity. Journal of Applied Psychology, 68(2), 320-333.

Fornell, C. \& Larcker, D. F. (1981). Evaluating Structural Equation Models with Unobservable Variables and Measurement Error. Journal of Marketing Research (JMR), 18(1), 39-50.

Fried, Y., Shirom, A., Gilboa, S. \& Cooper, C. L. (2008). The Mediating Effects of Job Satisfaction and Propensity to Leave on Role Stress-Job Performance Relationships: Combining Meta-Analysis and Structural Equation Modeling. International Journal of Stress Management, 15(4), 305-328.

Geisser, S. (1974). A Predictive Approach to the Random Effect Model. Biometrika, 61(1), 101-107.

Hair, J. F., Black, W. C., Babin, B. J., Anderson, R. E. \& Tatham, R. L. (2006). Multivariate Data Analysis (6th ed.). Upper Saddle River, NJ: Prentice Hall.

Hair, J. F., Hult, G. T. M., Ringle, C. M. \& Sarstedt, M. (2017). A Primer on Partial Least Squares Structural Equation Modeling. Thousand Oaks, CA: SAGE.

Hair, J. F., Ringle, C. M. \& Sarstedt, M. (2011). PLS-SEM: Indeed a Silver Bullet. Journal of Marketing Theory \& Practice, 19(2), 139-152. doi:10.2753/MTP1069-6679190202

Hair, J. F., Sarstedt, M., Ringle, C. M. \& Gudergan, S. P. (2018). Advanced Issues in Partial Least Squares Structural Equation Modeling. Thousand Oaks, CA: Sage.

Hausknecht, J. P., Trevor, C. O. \& Howard, M. J. (2009). Unit-Level Voluntary Turnover Rates and Customer Service Quality: Implications of Group Cohesiveness, Newcomer Concentration, and Size. Journal of Applied Psychology, 94(4), 1068-1075.

Heavey, A. L., Holwerda, J. A. \& Hausknecht, J. P. (2013). Causes and Consequences of Collective Turnover: A Meta-Analytic Review. The Journal Of Applied Psychology, 98(3), 412-453.

Henseler, J., Ringle, C. \& Sarstedt, M. (2015). A New Criterion for Assessing Discriminant Validity in VarianceBased Structural Equation Modeling. Journal of the Academy of Marketing Science, 43(1), 115-135.

Henseler, J., Ringle, C. M. \& Sinkovics, R. R. (2009). The Use of Partial Least Squares Path Modeling in International Marketing Advances in International Marketing, 8(20), 277-319.

Hom, P. W. \& Kinicki, A. J. (2001). Toward a Greater Understanding of How Dissatisfaction Drives Employee Turnover. Academy of Management Journal, 44(5), 975-987. 
Hom, P. W., Lee, T. W., Shaw, J. D. \& Hausknecht, J. P. (2017). One Hundred Years of Employee Turnover Theory and Research. The Journal of Applied Psychology, 102(3), 530-545.

Hom, P. W., Mitchell, T. R., Lee, T. W. \& Griffeth, R. W. (2012). Reviewing Employee Turnover: Focusing on Proximal Withdrawal States and an Expanded Criterion. Psychological Bulletin, 138(5), 831-858.

House, R. J., Schuler, R. S. \& Levanoni, E. (1983). Role Conflict and Ambiguity Scales: Reality or Artifacts? Journal of Applied Psychology, 68(2), 334-337.

Hu, J. \& Liden, R. C. (2011). Antecedents of Team Potency and Team Effectiveness: An Examination of Goal and Process Clarity and Servant Leadership. Journal of Applied Psychology, 96(4), 851-862.

Hulland, J. (1999). Use of Partial Least Squares (PLS) in Strategic Management Research: A Review of Four Recent Studies. Strategic Management Journal, 20(2), 195.

Jaramillo, F., Mulki, J. P. \& Solomon, P. (2006). The Role of Ethical Climate on Salesperson's Role Stress, Job Attitudes, Turnover Intention, and Job Performance. Journal of Personal Selling \& Sales Management, 26(3), 271-282.

Kahn, R. L., Wolfe, D. M., Quinn, R. P. \& Snoek, J. D. (1964). Organizational Stress: Studies in Role Conflict and Ambiguity. New York: John Wiley.

Karuppan, C. M. \& Karuppan, M. (2008). Resilience of Super Users' Mental Models of Enterprise-Wide Systems. European Journal of Information Systems, 17(1), 29-46.

Kemery, E. R., Bedeian, A. G., Mossholder, K. W. \& Touliatos, J. (1985). Outcomes of Role Stress: A Multisample Constructive Replication. Academy of Management Journal, 28(2), 363-375.

Kim, H. W. \& Kankanhalli, A. (2009). Investigating User Resistance to Information Systems Implementation: A Status Quo Bias Perspective. MIS Quarterly, 33(3), 567-582.

King, L. A. \& King, D. W. (1990). Role Conflict and Role Ambiguity: A Critical Assessment of Construct Validity. Psychological Bulletin, 107(1), 48-64.

Klaus, T. (2011). Understanding User Dissatisfaction: Exploring the Role of Fairness in IT-Enabled Change. Journal of Organizational \& End User Computing, 23(3), 1-25.

Low, G. S., Cravens, D. W., Grant, K. \& Moncrief, W. C. (2001). Antecedents and Consequences of Salesperson Burnout. European Journal of Marketing, 35(5/6), 587-611.

Maditinos, D., Chatzoudes, D. \& Tsairidis, C. (2012). Factors Affecting ERP System Implementation Effectiveness. Journal of Enterprise Information Management, 25(1), 60-78.

Mai, K. M., Ellis, A. P. J., Christian, J. S. \& Porter, C. O. L. H. (2016). Examining the Effects of Turn over Intentions on Organizational Citizenship Behaviors and Deviance Behaviors: A Psychological Contract Approach. The Journal Of Applied Psychology, 101(8), 1067-1081.

Markus, M. L. \& Tanis, C. (2000). The Enterprise System Experience: From Adoption to Success. In R. W. Zmud (Ed.), Framing the Domains of IT Management: Projecting the Future Through the Past (pp. 173-207). Cincinnati, Ohio: Pinnaflex Educational Resources.

Nah, F. F. H. \& Delgado, S. (2006). Critical Success Factors for Enterprise Resource Planning Implementation and Upgrade. Journal of Computer Information Systems, 47, 99-113.

Netemeyer, R. G., Brashear-Alejandro, T. \& Boles, J. S. (2004). A Cross-National Model of Job-Related Outcomes of Work Role and Family Role Variables: A Retail Sales Context. Journal of the Academy of Marketing Science, 32(1), 49-60.

Ojiako, U., Chipulu, M., Maguire, S., Akinyemi, B. \& Johnson, J. (2012). User Adoption of Mandatory Enterprise Technology. Journal of Enterprise Information Management, 25(4), 373-391.

Parker, S. K., Morgeson, F. P. \& Johns, G. (2017). One Hundred Years of Work Design Research: Looking Back and Looking Forward. The Journal Of Applied Psychology, 102(3), 403-420.

Peterson, M. F., Smith, P. B., Akande, A., Ayestaran, S., Bochner, S., Callan, V. \& Setiadi, B. (1995). Role Conflict, Ambiguity, and Overload: A 21-Nation Study. Academy of Management Journal, 38(2), 429-452.

Reinartz, W., Haenlein, M. \& Henseler, J. (2009). An Empirical Comparison of the Efficacy of Covariance-Based and Variance-Based SEM. International Journal of Research in Marketing, 26(4), 332-344.

Ringle, C. M., Wende, S. \& Becker, J. M. (2015). SmartPLS 3". Boenningstedt: SmartPLS GmbH.

Rivard, S. \& Lapointe, L. (2012). Information Technology Implementers' Responses to User Resistance: Nature and Effects. MIS Quarterly, 36(3), 897-A895.

Rizzo, J. R., House, R. J. \& Lirtzman, S. I. (1970). Role Conflict and Ambiguity in Complex Organizations. Administrative Science Quarterly, 15(2), 150-163. 
Sawyer, J. E. (1992). Goal and Process Clarity: Specification of Multiple Constructs of Role Ambiguity and a Structural Equation Model of Their Antecedents and Consequences. Journal of Applied Psychology, $77(2), 130-142$.

Shang, S. S. C. (2012). Dual Strategy For Managing User Resistance With Business Integration Systems. Behaviour \& Information Technology, 31(9), 909-925.

Singh, J., Goolsby, J. R. \& Rhoads, G. K. (1994). Behavioral and Psychological Consequences of Boundary Spanning Burnout for Customer Service Representatives. Journal of Marketing Research (JMR), 31(4), 558-569.

Smith, C. S., Tisak, J. \& Schmieder, R. A. (1993). The Measurement Properties of the Role Conflict and Role Ambiguity Scales: A Review and Extension of the Empirical Research. Journal of Organizational Behavior, 14(1), 37-48.

Sudhakar, G. P. (2012). A Model of Critical Success Factors for Software Projects. Journal of Enterprise Information Management, 25(6), 537-558.

Sykes, T. A. (2015). Support Structures and Their Impacts on Employee Outcomes: A Longitudinal Field Study of an Enterprise System Implementation. MIS Quarterly, 39(2), 473-A411. 